\title{
Pubertal hormones modulate the addition of new cells to sexually dimorphic brain regions
}

\author{
Eman I. Ahmed ${ }^{1}$, Julia L. Zehr ${ }^{1}$, Kalynn M. Schulz ${ }^{1,2}$, Betty H. Lorenz ${ }^{3,4}$, Lydia L. \\ DonCarlos $^{3}$, and Cheryl L. Sisk ${ }^{1,2}$ \\ ${ }^{1}$ Neuroscience Program, Michigan State University, East Lansing, MI 48824 \\ ${ }^{2}$ Department of Psychology, Michigan State University, East Lansing, MI 48824 \\ ${ }^{3}$ Dept. Cell Biology, Neurobiology and Anatomy, Loyola University Chicago, Maywood, IL 60153 \\ ${ }^{4}$ Neuroscience Program Stritch School of Medicine, Loyola University Chicago, Maywood, IL 60153
}

\begin{abstract}
New cells, including neurons, arise in several brain regions during puberty in rats. Sex differences in pubertal addition of cells coincide with adult sexual dimorphisms: for each region, the sex that gains more cells during puberty has a larger volume in adulthood. Removing gonadal hormones before puberty eliminates these sex differences, indicating that gonadal steroids direct the addition of new cells during puberty to maintain and accentuate sexual dimorphisms in the adult brain.
\end{abstract}

\section{Keywords}

sexual differentiation; sexual dimorphism; postnatal neurogenesis; puberty; gonadal hormones; AVPV; SDN; amygdala

\begin{abstract}
The establishment of structural sexual dimorphisms in the nervous system leads to life-long sex differences in physiology, learning and memory, social interactions, responses to stress and injury, and risk for disease ${ }^{1}$. Sexual differentiation of the nervous system is primarily attributable to actions of testosterone and its metabolites early in development ${ }^{2}$. It has been presumed that once established perinatally, sexual dimorphisms in cell number are passively maintained throughout life. Here we challenge this view by providing evidence that sexual dimorphisms are actively maintained, and that pubertal hormones contribute to the postnatal preservation of sexual dimorphisms via sex-specific modulation of new cells added to sexually dimorphic brain regions.
\end{abstract}

Male and female rats received injections of the cell birthdate marker bromo-deoxyuridine (BrdU) on three consecutive days at one of three postnatal ages corresponding to pre-puberty, early puberty, and mid-puberty (Supplementary Methods online). Brains were collected twenty days later, when all subjects were young adults. We analyzed BrdU-immunoreactive cells in three sexually dimorphic brain nuclei: the anteroventral periventricular nucleus of the

Correspondence: Cheryl L. Sisk, Neuroscience Program, 108 Giltner Hall, Michigan State University, East Lansing MI 48824, sisk@msu.edu, 517-355-5253 voice, 517-432-2744 fax.

Author Contributions

EIA, KMS, and CLS designed the experiments. EIA, KMS, and JLZ carried out the experiments, including BrdU injections, surgeries, and single label immunocytochemistry for BrdU. EIA and JLZ conducted the triple-label immunocytochemistry and corresponding confocal microscopic analyses. BHL and LLDC performed the double-label immunocytochemistry and corresponding confocal microscopic analyses. EIA wrote the initial draft of the manuscript, and CLS and LLDC wrote the short communication. EIA, KMS, JLZ, and BHL prepared figures and edited each manuscript draft. 
hypothalamus (AVPV), the sexually dimorphic nucleus of the preoptic area (SDN), and the medial amygdala (Me) (Fig. 1). The AVPV is larger in females, while the SDN and Me are larger in males. BrdU-labeled cells in these regions were frequently observed as closely apposed pairs, indicating that they may have divided in situ, as suggested by Kokoeva et $\mathrm{al}^{3}$. Quantification of BrdU-labeled cells revealed sex differences independent of the age at which BrdU was administered. The number of AVPV BrdU-labeled cells was higher in females than in males (Fig. 1a; $F_{1,27}=32.69, \mathrm{p}<0.0001$ ). In contrast, the number of BrdU-labeled cells in SDN (Fig. 1b; $F_{1,27}=27.45$, p $\left.<0.0001\right)$ and Me (Fig $1 \mathrm{c} ; \mathrm{F}_{1,30}=28.59$, $\left.\mathrm{p}<0.0001\right)$ was higher in males than in females. These sex differences in BrdU-labeled cell number correlated with sex differences in regional volume determined from analysis of Nissl-stained sections, i.e., AVPV volume was greater in females whereas SDN and Me volumes were greater in males (Supplemental Fig 1 online).

To determine the characteristics of BrdU-labeled cells, we labeled sections with BrdU and either neuron-specific nuclear protein (NeuN), a marker of mature neurons, or glial fibrillary acidic protein (GFAP), a marker of astrocytic glial cells, and assessed colocalization of proteins using confocal microscopy (Supplemental Methods online). Over half of the BrdU-labeled cells in the AVPV (Fig. 2a,b) also expressed NeuN, and none expressed GFAP. Approximately a quarter of BrdU-labeled cells in Me of both female and male rats also expressed NeuN, and an even greater number of BrdU-labeled cells in Me expressed GFAP (Fig 2c). BrdU-labeled cells in SDN expressed neither NeuN nor GFAP at detectable levels. In all of the regions, cells that did not colocalize NeuN or GFAP may be slated for apoptosis or for later differentiation in the event of functional demand. Alternatively, they may remain undifferentiated to support local neuronal or glial function in some manner.

To assess whether pubertal hormones modulate cell addition to sexually dimorphic brain regions, we gonadectomized male and female rats before puberty, injected them with BrdU for three consecutive days during early puberty, and collected brains three weeks later

(Supplemental Methods online). Gonadectomy interacted with sex to influence the number of BrdU-labeled cells in all three sexually dimorphic regions of interest. In the female-biased AVPV, prepubertal gonadectomy decreased BrdU-labeled cells in females but not males (Fig. $3 ; F_{1,24}=12.90, p<0.0015$, post hoc Fisher tests between groups). Prepubertal gonadectomy also resulted in a significant decrease in adult AVPV volume and neuron number only in females [Supplemental Fig 2 online]. Conversely, in the male-biased SDN and Me, gonadectomy decreased BrdU-labeled cells in males but not females (Fig 3; $\mathrm{SDN} \mathrm{F}_{1,26}=5.13$, $\left.\mathrm{p}<0.032 ; \mathrm{Me} \mathrm{F}_{1,27}=10.24, \mathrm{p}<0.004\right)$. The effect of male gonadectomy on SDN and Me BrdUlabeled cells was paralleled by a significant decrease in volume of the adult SDN, but not the Me (Supplemental Fig. 2 online). In contrast, neither sex $\left(\mathrm{F}_{1,26}=1.12\right.$, $\left.\mathrm{p}=0.3\right)$ nor prepubertal gonadectomy $\left(\mathrm{F}_{1,26}=1.39, \mathrm{p}=0.25\right)$ affected the number of BrdU-labeled cells in the dentate gyrus (Fig 3), which is not overtly larger in either sex. Gonadal steroids may influence the pubertal addition of new cells and maintenance of sex differences by brain region-specific modulation of either cell proliferation and differentiation ${ }^{4-6}$ or survival $^{7}$.

These data provide strong evidence that sex-biased, hormone-modulated, and brain regionspecific addition of new cells is an active mechanism for maintaining, or in some cases, establishing, structural and functional sexual dimorphisms in the face of brain remodeling during adolescence ${ }^{8}$. This mechanism may be widespread, as both the volume and number of cells increase during puberty in the female-biased rat locus coeruleus ${ }^{9}$ and the male-biased human bed nucleus of the stria terminalis ${ }^{10}$. Addition of new cells may also be related to functional sex differences that emerge during puberty. For example, the rat AVPV controls the preovulatory surge of luteinizing hormone ${ }^{11}$, an estrogen-dependent event that emerges during puberty only in females in parallel with development of sex differences in AVPV volume ${ }^{12-13}$. Likewise, sex differences in structure and function of the human amygdala and 
in several mental illnesses, such as eating disorders, depression, and schizophrenia, arise during adolescent development ${ }^{14-15}$. An intriguing question remains whether sex-biased addition and survival of new cells in sexually dimorphic brain regions continues beyond the pubertal period. If so, this could contribute to a dynamic maintenance of functional sexual dimorphisms throughout adulthood to preserve the potential for adaptation to new experiences and functional demands (e.g., pregnancy, parental behavior). In summary, new cells are added to the rat brain during puberty, and sex differences in the number of newly added cells correspond to sex differences in adult volume in each region. Furthermore, pubertal gonadal hormones influence the addition of new cells, presumably by promoting cell genesis and/or survival in sexually dimorphic structures in a sex-specific manner. Thus, hormone-modulated addition of cells to sexually dimorphic neural structures after the perinatal period is an active mechanism for maintaining functional sex differences during adolescence and into adulthood.

\section{Supplementary Material}

Refer to Web version on PubMed Central for supplementary material.

\section{Acknowledgments}

The technical support of Jane Venier and Lisa Rogers is gratefully acknowledged. We thank Dr. Melissa Holmes for her technical and intellectual insight during protocol development. This work was supported by R01 MH-068764 (CLS), F32 MH-068975 (JLZ), F31 MH-070125 (KMS), the Michigan State University Foundation (CLS, EIA), R01 MH-062588 (LLDC), and the Schmitt Foundation (BHL).

\section{References}

1. Cahill L. Nat. Rev. Neuroscience 2006;7:477-484.

2. De Vries, GJ.; Simerly, RB. Hormones, Brain, and Behavior. Pfaff, DW.; Etgen, AM.; Fahrbach, SE.; Rubin, RT., editors. Academic Press; San Diego: 2002. p. 137-191.

3. Kokoeva MV, Yin H, Flier JS. J. Comp. Neurol 2007;505:209-220. [PubMed: 17853440]

4. Fowler CD, Johnson F, Wang Z. J. Comp. Neurol 2005;489:166-179. [PubMed: 15984004]

5. Tanapat P, Hastings NB, Reeves AJ, Gould E. J. Neurosci 1999;19:5792-5801. [PubMed: 10407020]

6. Galea LAM. Brain Res. Rev 2008;57:332-341. [PubMed: 17669502]

7. Forger NG. Neuroscience 2006;138:929-938. [PubMed: 16310316]

8. Sisk CL, Zehr JL. Frontiers in Neuroendocrinology 2005;26:163-174. [PubMed: 16309736]

9. Pinos H, et al. Brain Res. Bull 2001;56:73-78. [PubMed: 11604252]

10. Chung WCJ, De Vries GJ, Swaab DF. J. Neurosci 2002;22:1027-1033. [PubMed: 11826131]

11. Petersen SL, Ottem EN, Carpenter CD. Biol. Reprod 2003;69:1771-1778. [PubMed: 12890720]

12. Hoffman GE, Le WW, Schulterbrandt T, Legan SJ. Brain Res 2005;1054:116-124. [PubMed: 16084918]

13. Davis EC, Shryne JE, Gorski RA. Neuroendocrinology 1996;63:142-148. [PubMed: 9053778]

14. Lenroot RK, Giedd JN. Neurosci. Biobehav. Rev 2006;30:718-729. [PubMed: 16887188]

15. Killgore WDS, Yurgelun-Todd DA. Perceptual and Motor Skills 2004;99:371-391. [PubMed: 15560325] 
a

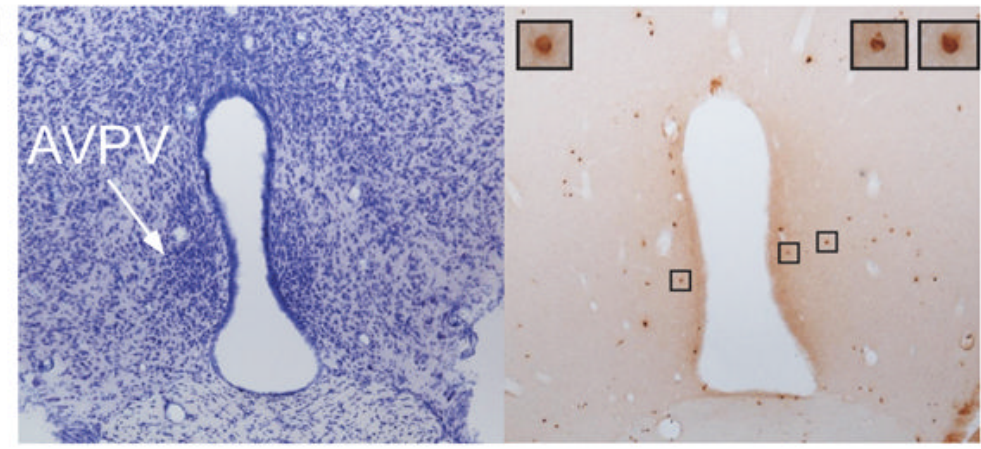

b

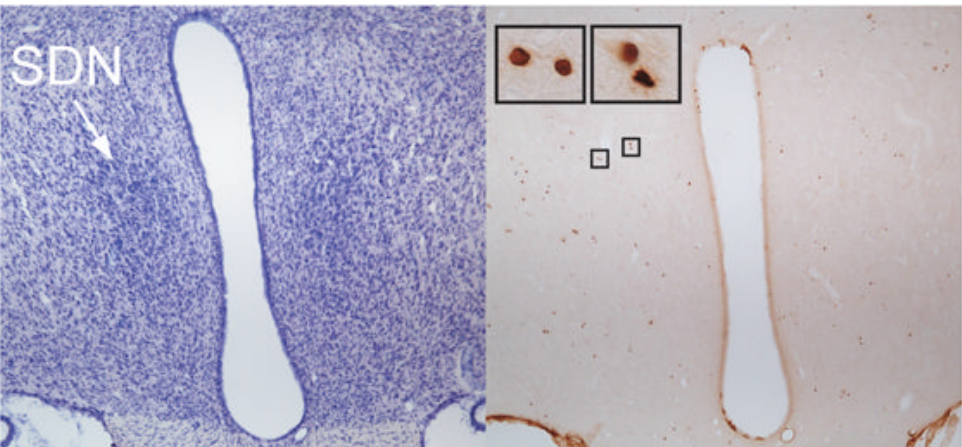

C

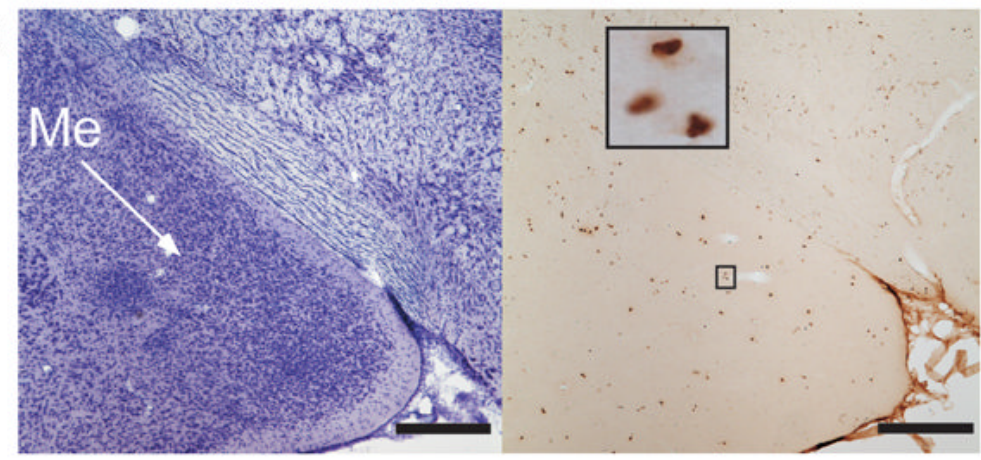

Nissl

\section{BrdU}
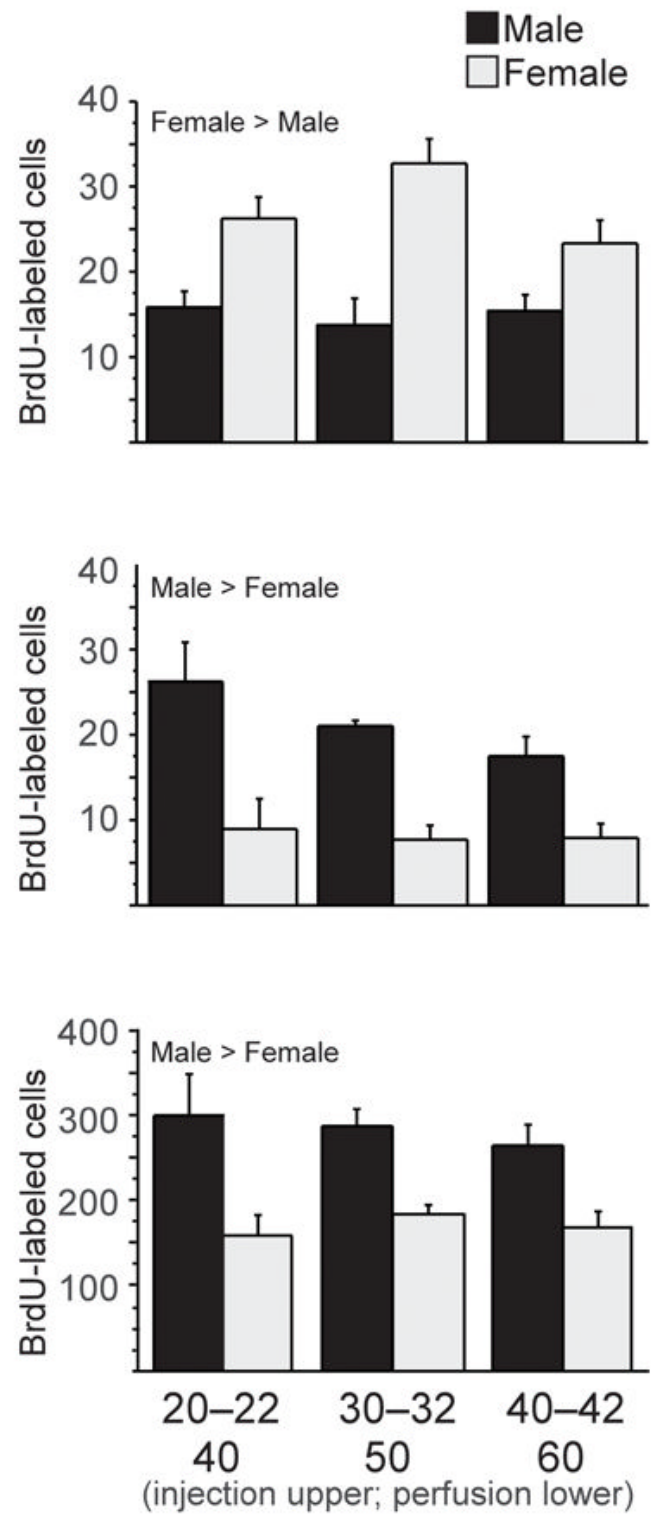

Age (d)

Figure 1.

New cells are added during puberty to the AVPV (a), SDN (b), and Me (c) in male and female rats. Left photomicrographs are of thionin-stained sections and right photomicrographs are of BrdU-labeled cells in nearby sections from the same animal. Insets show BrdU-labeled cells framed in small boxes at 10x higher magnification. Subjects received a daily injection of 300 $\mathrm{mg} / \mathrm{kg} \mathrm{BrdU}$ on three consecutive days on either 20-22, 30-32, or 40-42 days of age ( $\mathrm{n}=6-8 /$ age and sex). BrdU is incorporated into DNA during the $S$ phase of the cell cycle and can be later visualized to identify cells replicating at the time of BrdU administration. Brain tissue was collected 20 days after the first BrdU injection, on 40, 50, or 60 days of age, respectively. All protocols involving animals were approved by the Michigan State University Institutional Animal Care and Use Committee. Quantitative analyses of BrdU-labeled cells revealed that during puberty, significantly more cells were added to AVPV (a) in females than in males, 
while significantly more cells were added to SDN (b) and Me (c) in males than in females. Data are means \pm SEM. Scale bars: $250 \mu \mathrm{m}$ in lower magnification images. 


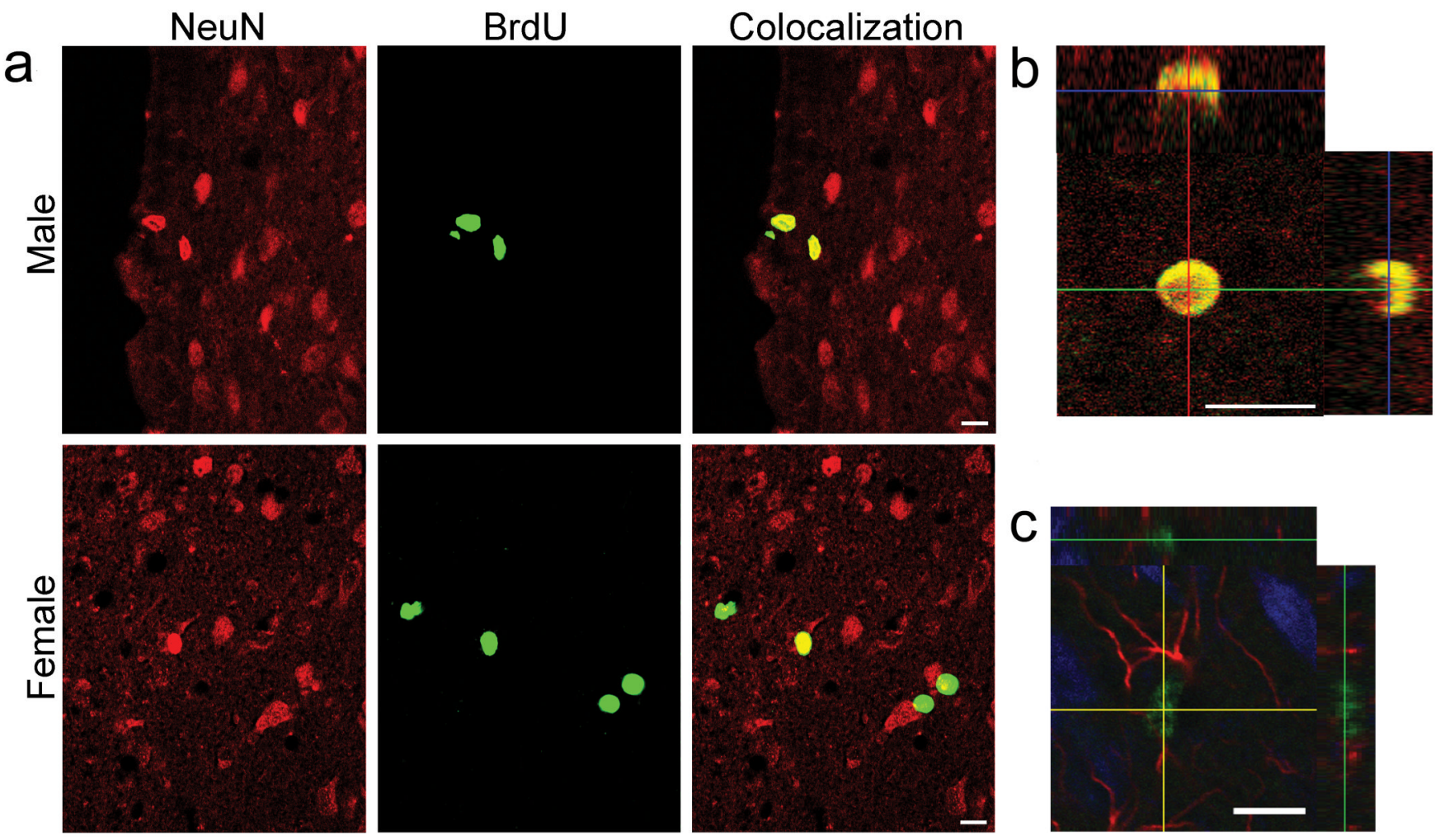

Figure 2.

Many BrdU-labeled cells in the AVPV are mature neurons, not astrocytes. Many BrdU-labeled cells in Me are astrocytes; some are neurons. a: Confocal images of cells in male and female rat AVPV. Sections were processed for double-label BrdU (green) and the mature neuron marker NeuN (red); colocalization is yellow. b: Orthogonal views of confocal images verify colocalization of BrdU and NeuN in the female AVPV of a neuron that was born on P30-32. c: Confocal image of cells in rat Me. Section was processed for triple-label BrdU (green), NeuN (blue), and the astrocytic glial marker GFAP (red). Orthogonal views verify colocalization of BrdU, which is in the nucleus, and GFAP, which is in astrocytic processes. Scale bars: $10 \mu \mathrm{m}$. 
Sham
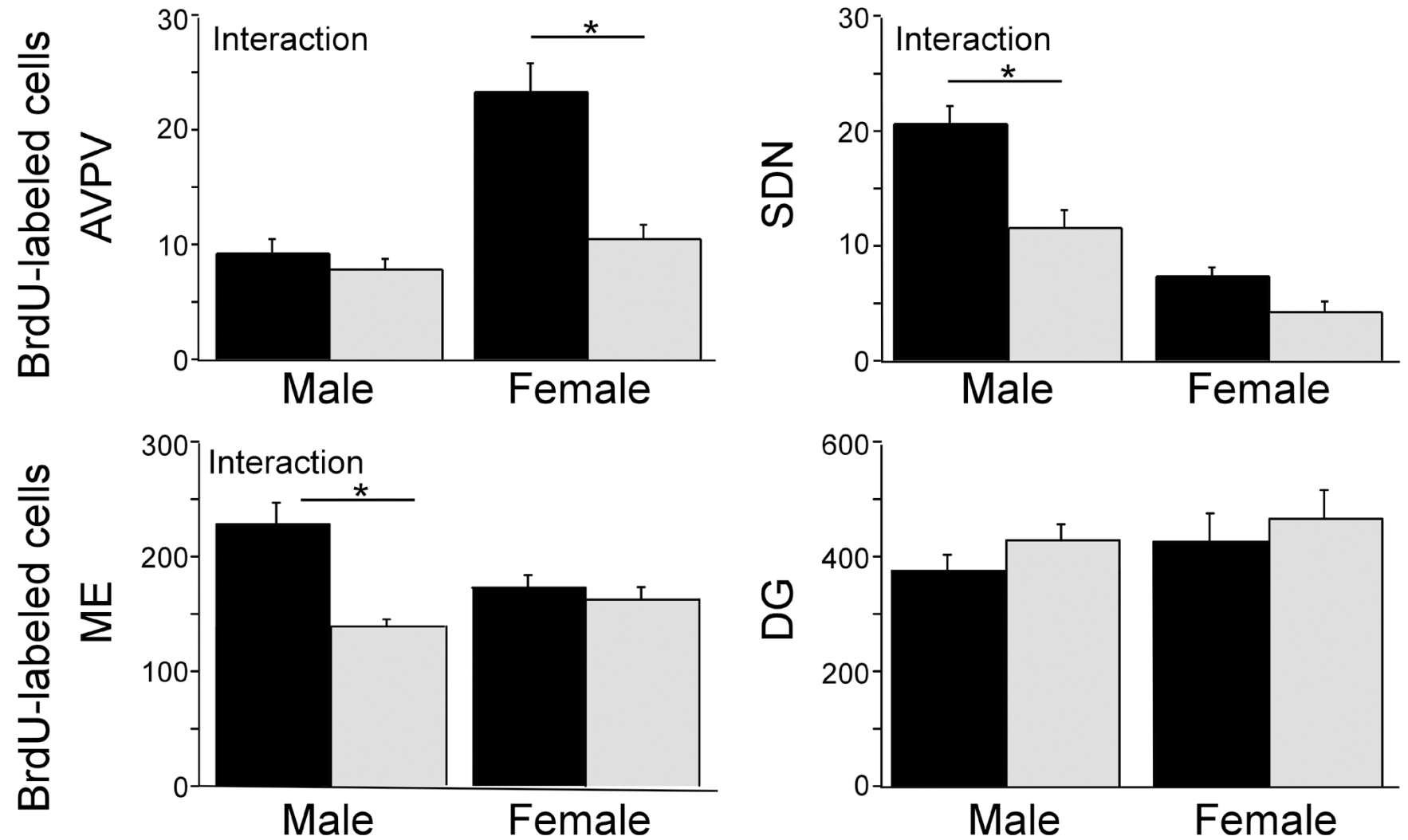

Figure 3.

The effect of prepubertal gonadectomy (GDX) on the number of BrdU-labeled cells depends on sex and brain region. Male and female rats were gonadectomized or sham gonadectomized at 20 days of age ( $n=8 /$ sex and treatment). A daily injection of BrdU was given on 30-32 days of age and brain tissue was collected at 50 days of age. Prepubertal GDX significantly decreased the number of BrdU-labeled cells in female but not male AVPV (interaction between sex and treatment). Prepubertal GDX decreased the number of BrdU-labeled cells in male but not female SDN and Me (interaction between sex and treatment). Prepubertal GDX did not affect BrdU-labeled cells in the dentate gyrus (DG) of either males or females. Data are presented as means \pm SEM. Asterisks indicate $\mathrm{p}<0.05$ (post hoc Fisher test between groups). 